\title{
ANALISIS KEBIASAAN MEROKOK DAN KONSUMSI OBAT ANALGETIK SEBAGAI FAKTOR RESIKO PENYAKIT GAGAL GINJAL KRONIS
}

\author{
Diyono ${ }^{1}$
}

\begin{abstract}
Background: Chronic Renal Failure (CRF) is a chronic degenerative disease that requires great attention. This is not only because of the ever-increasing incidence, but also because of the maintenance process that takes time and enormous expenses. Globally, nationally and regionally, chronic renal failure tends to increase. The most effective therapy for chronic renal failure is the prevention of risk factors.

Objectives: Identify of smokingand analgetic drug consumption as a risk factor for chronic renal failure.

Methode: This research is a correlation research with case control design. The sample were 75 case study groups and 75 control groups. Data obtained through interviews and analyzed using multiple logistic regression with SPSS series 18.

Result: Smoking habit $(p=0.625)$ and analgetik consumption $(p=0.069$ had no effect on the incidence of chronic renal failure.

Conclusion: Research conclusions are smoking and analgetik consumption had no effect on the incidence of chronic renal failure
\end{abstract}

Keywords: Analgetik consumption, Chronic Renal Failure, smoking

\section{PENDAHULUAN}

Gagal Ginjal Kronis (GGK) merupakan penyakit degeneratif kronis yang membutuhkan perhatian besar. Hal ini bukan hanya karena insiden yang terus meningkat, namun juga karena proses perawatan yang membutuhkan waktu dan biaya yang sangat besar. Insiden penyakit gagal ginjal kronik di Indonesia cenderung meningkat. Pada tahun 2011 terdapat sekitar 30,7 per juta populasi dengan prevalensi sekitar 23.4 per juta populasi (IRR, 2011). Kasus gagal ginjal di Jawa Tengah yang paling tinggi adalah di Kota Surakarta dengan 1497 kasus (25.22 \%) dan diposisi kedua adalah Kabupaten Sukoharjo yaitu 742 kasus atau $12.50 \%$ (Dinkes Jawa Tengah, 2008).

Cuci darah merupakan terapi gagal ginjal pilihan utama, namun mempunyai dampak yang luas baik secara fisik, sosial, dan ekonomi. Penelitian McKercher et al. (2013), membuktikan bahwa penyakit
Chronic Kidney Desease mempengaruhi psikososial dan kecemasan pasien dan sebaliknya keadaan psikososial dan kecemasan pasien juga akan berpengaruh terhadap proses patologi penyakit Chronic Kidney Desease.

Gagal ginjal kronis adalah penurunan atau hilangnya fungsi ginjal yang bersifat ireversibel yang ditandai kegagalan ginjal menjaga keseimbangan cairan, metabolisme dan elektrolit (Smeltzer dan Bare, 2010).

Penyebab penurunan nefron dapat terjadi akibat penyakit sistemik seperti diabetus melitus, hipertensi, glumerulonefritis dan penyakit autoimun (William dan Hopper, 2003).

Peningkatan kejadian penyakit gagal ginjal kronis terkait erat dengan perubahan perilaku atau sering disebut dengan gaya hidup (lifestyle) dari seseorang. Penelitian Chang, et al (2013) pada pasien yang mengikuti program Kidney 
Early Evaluation Program (KEEP) di National Kidney Foundation Miniapolis menunjukkan bahwa faktor resiko gagal ginjal kronis tahap akhir (End Stage Renal Desease/ESRD) paling banyak karena penyakit diabetus melitus dan hipertensi dimana kedua penyakit tersebut terjadi karena gaya atau pola hidup yang tidak sehat.

Hasil penelitian Restianika tahun 2014 di RSUD Dr. Suroto Ngawi Jawa Timur juga memberikan bukti bahwa gaya hidup berupa kebiasaan mengkonsumsi minuman suplemen energi merupakan faktor resiko utama gagal ginjal kronis, selain merokok dan konsumsi kopi.

\section{TUJUAN PENELITIAN}

Penelitian bertujuan untuk mengetahui hubungan kebiasaan merokok dan konsumsi obat analgetik sebagai faktor resiko penyakit gagal ginjal kronik.

\section{METODE/DESAIN PENELITIAN}

Penelitian ini merupakan penelitian observasi analitik (analytic observasional) dengan desain case control, dilakukan dengan cara melakukan penelusuran gaya hidup 75 pasien gagal ginjal kronis yang dilakukan hemodialisa di RUMAH SAKIT Dr. OEN SURAKARTA Jawa Tengah, dibandingkan dengan 75 responden sehat atau tidak terdiagnosa penyakit gagal ginjal kronis.

Data dikumpulkan dengan pedoman wawancara dan dianalisa menggunakan uji regresi logistk ganda dengan bantuan program SPSS seri 18. Pengaruh dari masing - masing variabel ditentukan berdasar nilai $p$ (tingkat kemaknaan) dan nilai OR (Odd Rasio).

\section{HASIL PENELITIAN DAN PEMBAHASAN}

Penelitian dilaksanakan mulai Pebruari - Juni 2017 di RUMAH SAKIT Dr. OEN SURAKARTA dan Kecamatan Polokarto Kabupaten Sukoharjo.

1. Data Demografi

Tabel 1.

Gambaran Data Demografi

\begin{tabular}{lcccc}
\hline \multirow{2}{*}{ Variabel } & \multicolumn{2}{c}{ Kasus } & \multicolumn{2}{c}{ Kontrol } \\
\cline { 2 - 5 } & $f$ & $\%$ & $f$ & $\%$ \\
\hline Jenis Kelamin & & & & \\
Laki-Laki & 42 & 56.0 & 42 & 56.0 \\
Perempuan & 33 & 44.0 & 33 & 44.0 \\
Umur & & & & \\
20-40 & 16 & 21.3 & 0 & 00.0 \\
$41-60$ & 45 & 60.0 & 17 & 22.7 \\
$>60$ & 14 & 18.7 & 58 & 77.3 \\
Pekerjaan & & & & \\
IRT & 23 & 30.7 & 13 & 17.3 \\
Buruh & 4 & 05.3 & 5 & 06.7 \\
Petani & 6 & 08.0 & 5 & 06.7 \\
Dagang & 2 & 02.7 & 2 & 02.7 \\
Swasta & 27 & 36.0 & 2 & 02.7 \\
PNS & 8 & 10.7 & 4 & 05.3 \\
TNI & 3 & 04.0 & 2 & 02.7 \\
Satpam & 1 & 01.3 & 0 & - \\
Sopir & - & - & 2 & 02.7 \\
Mahasiswa & 1 & 01.3 & - & - \\
Guru & - & - & 3 & 04.0 \\
\hline
\end{tabular}

Dari Tabel 1 di atas memberikan informasi demografis dimana berdasar jenis kelamin kedua kelompok mempunyai persentase yang sama, yaitu laki - laki lebih banyak daripada perempuan yaitu $56.0 \%$ berbanding dengan $44.0 \%$. Umur paling banyak kelompok kasus usia 41- 60 tahun (60\%), sedang pada kelompok kontrol paling banyak usia lebih dari 60 tahun sebanyak $77.3 \%$. Pekerjaan responden yang paling banyak adalah Ibu Rumah Tangga (IRT) yaitu $30.7 \%$ dan $17.3 \%$. 
2. Faktor Resiko Gagal Ginjal Kronis

Tabel 2.

Distribusi Frekwensi Faktor Resiko Penyakit

\begin{tabular}{lcccc}
\hline \multirow{2}{*}{ Variabel } & \multicolumn{2}{c}{ Kasus } & \multicolumn{2}{c}{ Kontrol } \\
\cline { 2 - 4 } & f & $\%$ & f & $\%$ \\
\hline DM & 15 & 20.0 & & \\
Hipertensi/HT & 27 & 36.0 & & \\
DM+HT & 14 & 18.7 & & \\
Tidak & 19 & 20.3 & & \\
\hline
\end{tabular}

Dari Tabel 2 memberikan informasi dari seluruh kelompok kasus yaitu yang mengalami sakit gagal ginjal kronis $20 \%$ mempunyai riwayat penyakit dahulu diabetus melitus (DM), 36\% mempunyai riwayat hipertensi, yang mempunyai riwayat hipertensi dan DM $18.7 \%$ dan yang tidak mempunyai kedua-duanya sebanyak $20.3 \%$.

Tabel 3.

Distribusi Faktor Resiko Kebiasaan Merokok dan Konsumsi Obat Analgetik

\begin{tabular}{ccccc}
\hline \multirow{2}{*}{ Variabel } & \multicolumn{2}{c}{ Kasus } & \multicolumn{2}{c}{ Kontrol } \\
\cline { 2 - 5 } & $\mathrm{f}$ & $\%$ & \multicolumn{1}{c}{$\mathrm{f}$} & $\%$ \\
\hline \multicolumn{4}{l}{ Lama Kebiasaan Merokok (Tahun) } \\
$1-10$ & 4 & 10,3 & 17 & 47,2 \\
$11-20$ & 12 & 30.8 & 10 & 27.8 \\
$>20$ & 23 & 59.0 & 9 & 25.0 \\
Konsumsi & Obat Analgetik \\
Ya & 5 & 11,6 & 1 & 3.2 \\
Tidak & 38 & 88,4 & 30 & 96,8 \\
\hline
\end{tabular}

Seperti terlihat pada Tabel 3 tentang faktor resiko penyakit gagal ginjal kronis memberikan informasi perbandingan kebiasaan yang dilakukan kelompok kasus dan kelompok kontrol bahwa faktor resiko kebiasaan merokok dengan lama merokok > 20 tahun pada kelompok kasus lebih banyak daripada kelompok kontrol yaitu $59.0 \%$ berbanding $25.0 \%$. Sedangkan untuk kebiasaan minum kopi pada kelompok kasus sebanyak $25.3 \%$ lebih sedikit daripada kelompok kontrol yang mencapai $32.0 \%$. Faktor resiko pola konsumsi obat analgetik secara bebas atau tidak menggunakan resep dokter untuk kelompok kasus lebih kecil yaitu $88.4 \%$ sedangkan pada kelompok kontrol mencapai $96.8 \%$.

\section{Analisis Multivariat}

Tabel 4.

Hasil Analisa Multivariat dengan Regresi Logistik Ganda

\begin{tabular}{|l|c|c|}
\hline Variabel & $X^{2}$ & Sig \\
\hline Merokok & 0.624 & ${ }^{*}$ \\
\hline Analgetik & 0.005 & 0.069 \\
\hline
\end{tabular}

\begin{tabular}{|l|c|c|c|}
\hline \multirow{2}{*}{ Variabel } & \multirow{2}{*}{$\operatorname{Exp}(\mathrm{B})$} & \multicolumn{2}{|c|}{$\mathrm{Cl} 95 \%$} \\
\cline { 3 - 4 } & & $\mathrm{Up}$ & $\mathrm{Lw}$ \\
\hline Merokok & $*$ & $*$ & ${ }^{*}$ \\
\hline Analgetik & 0,513 & 0.25 & 10 \\
\hline
\end{tabular}

${ }^{*}$ Tidak dilanjutkan proses karena nilai $X^{2}>0.05$

Dari Tabel 4 memberikan penjelasan bahwa berdasar hasil uji statistik multivariat dengan uji regresi logistik ganda menunjukkan nilai $\mathrm{x}^{2}$ dan Sig > 0.05 sehingga dapat diambil kesimpulan kebiasaan merokok dan konsumsi obat analgetik tidak berpengaruh secara signifikan terhadap kejadian penyakit gagal ginjal kronis.

\section{PEMBAHASAN}

Hasil penelitian menunjukkan kebiasaan merokok tidak berpengaruh secara signifikan sebagai faktor resiko gagal ginjal kronis $(p=0.624)$. Hasil penelitian ini berbeda dengan penelitian Pranandari dan Supadmi (2015), yang menyimpulkan kebiasaan merokok hampir 2 (dua) kali meningkatkan resiko gagal ginjal kronis daripada individu atau kelompok yang tidak merokok $(p=0.043 ; \quad \mathrm{OR}=1.987) . \quad$ Hasil penelitian ini juga berbeda dengan hasil penelitian yang dilakukan oleh Hidayati, Kushadiwijaya dan Suhardi 
(2013) yang memperoleh kesimpulan bahwa kebiasaan merokok merupakan faktor resiko gagal ginjal dengan tingat resiko 3.68 (Cl:1.39 - 9.74).

Kebiasaan merokok atau asap rokok meningkatkan resiko gangguan pembuluh darah yang bermuara pada penyakit jantung hipertensi sebagai salah satu resiko gagal ginjal (Hallan dan Orth, 2011). Secara patologis asap rokok membutuhkan waktu yang sangat lama yaitu lebih dari 5 atau 10 tahun untuk dapat menimbulkan kerusakan sel, jaringan dan organ tubuh sehingga muncul masalah atau gangguan kesehatan. Asap rokok yang lama dan sering masuk ke dalam saluran pernapasan secara langsung maupun tidak langsung akan menyebabkan peningkatan resiko arterosklerosis. Selain itu nikotin yang ada pada asap rokok akan meningkatkan kadar katekolamin tubuh sehingga meningkatkan denyut jantung (heart rate) dan meningkatkan resiko hipertensi. Hipertensi yang berlangsung lama akan menyebabkan terjadinya resiko gagal atau payah jantung yang ditandai penurunan pompa jantung atau kardiak output. Penurunan kardiak output inilah yang kemudian secara perlahan-lahan dan menahun dapat menyebabkan hypoksia dan kerusakan nefron ginjal. Proses patologi yang cukup panjang inilah yang memungkinkan pada penelitian ini tidak langsung dapat menjelaskan peran kebiasaan merokok terhadap resiko gagal ginjal kronis (William dan Hopper, 2003). Hasil penelitian yang sejalan dengan hasil penelitian ini adalah penelitian Floresia (2015) yang menyimpulkan bahwa riwayat merokok dan lama merokok tidak mempunyai pengaruh terhadap kejadian gagal ginjal konis $(n=192$; $p=0.833$ ). Data demografis pada penelitian ini juga mendukung bahwa pada kelompok kasus (sakit gagal ginjal kronis) paling banyak mempunyai kebiasaan merokok lebih dari 20 tahun.

Walaupun hasil penelitian ini tidak menunjukkan adanya hubungan secara langsung kebiasaan merokok dengan faktor resiko gagal ginjal kronis yang berarti kebiasaan merokok tidak langsung meningkatkan kejadian penyakit gagal ginjal kronis, namun data pada kelompok kasus yaitu yang mengalami gagal ginjal kronis terlihat $79.7 \%$ mengalami penyakit hipertensi, diabetus melitus, atau kedua-duanya. Penyakit-penyakit tersebut merupakan penyakit yang salah satu faktor resikonya adalah kebiasaan merokok atau terpapar asap rokok. Selain itu penyakitpenyakit tersebut juga merupakan faktor resiko utama dari penyakit gagal-ginjal kronis. Uraian tersebut memberikan penjelasan kebiasaan merokok tidak langsung menyebabkan penyakit gagal ginjal kronis, namun menyebabkan penyakit-penyakit yang menjadi faktor resiko gagal ginjal kronis. Hal tersebut sesuai dengan konsep yang disampaikan oleh William dan Hopper (2003) yang menyebutkan selain karena kelanjutan dari gagal ginjal akut, gagal ginjal kronis dapat disebabkan karena kondisi penyakit sistemik terutama diabetus melitus dan hipertensi.

Hasil penelitian memperlihatkan bahwa konsumsi obat analgetik tidak mempunyai pengaruh terhadap kejadian gagal ginjal kronis $(p=0.069)$. Hasil penelitian ini berbeda dengan hasil penelitian Gooch, et al (2007) menunjukkan bahwa konsumsi NSAID yang tidak terkontrol meningkatkan resiko gagal ginjal kronis sebesar 1.26 kali dan penelitian Kurth, et al (2003) yang juga memberikan hasil bahwa konsumsi analgetik NSAID seperti aspirin yang berlebihan akan 1.22 kali meningkatkan resiko kerusakan 
filtrasi glumerulus. Tidak adanya hubungan yang bermakna kebiasaan konsumsi obat analgetik sebagai faktor resiko penyakit gagal ginjal pada penelitian ini, dimungkinkan karena rata-rata responden tidak mengkonsumsi obat dalam waktu yag lama dan sering. Peningkatan resiko gagal ginjal akibat konsumsi analgetik, terjadi jika konsumsi obat dalam waktu yang lama dan jumlah yang banyak, sedang pada penelitian ini rata-rata responden lupa berapa banyak dan berapa lama mengkonsumsi analgetik. Penelitian Kurth, et al (2003) memperlihatkan pasien yang telah mengkonsumsi obat anti nyeri secara tidak tepat (lebih dari satu pil dalam seminggu) sepanjang kurun waktu 2 tahun atau lebih untuk menghilangkan rasa sakit beresiko mengalami kerusakan ginjal.

\section{KESIMPULAN}

1. Kebiasaan merokok maupun konsumsi obat analgetik tidak berpengaruh terhadap peningkatan resiko penyakit gagal ginjal kronis.

2. Kebiasaan merokok dalam waktu yang lama dapat meningkatkan kejadian penyakit hipertensi dan diabetus melitus sebagai faktor resiko gagal ginjal kronis.

\section{SARAN}

1. Perawat dapat memberikan motivasi kepada pasien untuk menurunkan kebiasaan merokok sebagai langkah meurunkan resiko gagal ginjal kronis.

2. Rumah sakit dan fasilitas kesehatan lainya diharapkan dapat membuka layanan konsultasi tentang cara pencegahan dan deteksi dini penyakit gagal ginjal kronis

3. Untuk peneliti selanjutnya diharapkan dapat melakukan penelitian yang lebih komprehensif tentang faktorfaktor lain yang mempengaruhi kejadian penyakit gagal ginjal kronis, misalnya faktor penyakit hipertensi, diabetus melitus serta pola hidup yang lain misalnya konsumsi alkohol, olah raga dan lain-lain.

\section{DAFTAR PUSTAKA}

Chang, T. I., et al. 2013. Risk Factors for ESRD in Individuals With Preserved Estimated GFR With and Without Albuminuria: Results From the Kidney. Early Evaluation Program (KEEP). The National Kidney Foundation, Inc. Published by Elsevier Inc. Diunduh 14 Maret 2016.

Dinas Kesehatan Propinsi Jawa Tengah. 2008. Profil Kesehatan Propinsi Jawa Tengah Tahun 2008.

Gooch, et al. 2007. NSAID Use and Progression of Chronic Kyney Desease. The American Journal of Medicine. Volume 120. Issue 3.

Hallan S. I. dan Stephan R. Orth. 2011. Smoking is a risk factor in the progression to kidney failure. International Society of Nephrology. Diunduh 16 Maret 2016.

Hidayati, H. Kushadiwijaya dan Suhardi. 2013. Hubungan Antara Hipertensi, Merokok, dan Minuman Suplen Energi dan Kejadian Penyakit Ginjal Konik. Berita Kedokteran Masyarakat. Volume 24 No.2.

IRR (Indonesian Renal Registry). 2011. Report of Indonesian Renal Registry. Edisi IV. Jakarta.

Kurth, et al. 2003. Analgesic Used and Change in Kydney Function in Apparently Healthy Men. American Jounal of Kydney Deseases. Volume 42. Issue 2. 
McKercher, C.M. et.al. 2013. "Psychosocial factors in adults with chronic kidney disease: characteristics of pilot participants in the Tasmanian Chronic Kidney Disease Study". BioMed Centrall (BMC) Nephrology.14:83. Diunduh 18 Maret 2016.

Pranandari, Restu dan Woro Supadmi. 2015. Faktor Resiko Gagal Ginjal Kronik di Unit Hemodialisis RSUD Wates Kulonprogo.

http://mf.farmasi.ugm.ac.id/files/3 34.pdf.

Restianika, N. 2014. Faktor Yang Berhubungan Dengan Kejadian Gagal Ginjal Kronik Pada Pasien Rawat Inap Ruang Penyakit Dalam Di RSUD dr.Soeroto Kabupaten Ngawi. Skripsi. Universitas Jember. Diunduh 18 Maret 2016.
Smeltzer, S. C. dan B. G. Bare. 2010. Brunner and Suddarth's Text Book of Medical Surgical Nursing. $10^{\text {th }}$ edition. Lippincot and Williams.

William, Linda S. dan Paula D. Hopper. 2003. Understanding Medical Surgical Nursing, $2^{\text {nd }}$ edition. Davis Company, Philadephia. USA.

${ }^{1}$ Dosen Akper Panti Kosala Surakarta 